\title{
Evaluation of phenylethylamine type entactogens and their metabolites relevant to ecotoxicology - a QSAR study
}

\author{
MILENA JADRIJEVIĆ-MLADAR TAKAČ ${ }^{1, *}$ \\ JOAO DANIEL CASIMIRO MAGINA ${ }^{2}$ \\ TIN TAKAČ ${ }^{3}$ \\ ${ }^{1}$ University of Zagreb Faculty of \\ Pharmacy and Biochemistry, Department \\ of Medicinal Chemistry, 10000 Zagreb \\ Croatia \\ ${ }^{2}$ Universidade de Lisboa, Faculdade de \\ Farmácia, 1649-004 Lisboa, Portugal \\ ${ }^{3}$ University of Zagreb Faculty of \\ Chemical Engineering and Technology \\ 10000 Zagreb, Croatia
}

\begin{abstract}
The impact of the selected entactogens and their $o$-quinone metabolites on the environment was explored in QSAR studies by the use of predicted molecular descriptors, ADMET properties and environmental toxicity parameters, i.e., acute toxicity in Tetrahymena pyriformis (TOX_ATTP) expressed as Th_pyr_pIGC $C_{50} / \mathrm{mmol} \mathrm{L}^{-1}$, acute toxicity in Pimephales promelas, the fathead minnow (TOX_FHM) expressed as Minnow $L C_{50} / \mathrm{mg} \mathrm{L}^{-1}$, the acute toxicity in Daphnia magna (TOX_DM) expressed as Daphnia $L_{50} / \mathrm{mg} \mathrm{L}^{-1}$ and bioconcentration factor (BCF).

The formation of corresponding o-quinones via benzo-dioxolone ring, $\mathrm{O}$-demethylenation was predicted as the main metabolic pathway for all entactogens except for 1-(2,2-difluorobenzo[d][1,3]dioxol-5-yl)propan-2-amine (DiFMDA). The least favourable ADMET profile was revealed for $\mathrm{N}$-(1-(benzo[d][1,3]dioxol-5-yl)propan-2-yl)-Omethylhydroxylamine (MDMEO).

QSAR studies revealed significant linear correlations between $M \log P$ of entactogens and $M \log P$ of $o$-quinone metabolites $(R=0.99)$, and Th_pyr_pIGC $C_{50} / \mathrm{mmol} \mathrm{L}^{-1}(R=0.94)$, also their $M \log P$ s with Minnow_LC $C_{50} / \mathrm{mg} \mathrm{L}^{-1}(R=0.80$ and $R=$ $0.78), \mathrm{BCF}(R=0.86$ and $R=0.82)$ and percentage of $o$-quinones' yields $(R=0.73$ and $R=0.80)$. Entactogens were predicted as non-biodegradable molecules, whereas the majority of their $o$-quinones were biodegradable.
\end{abstract}

Keywords: entactogens, ecstasy, ADMET, CYP metabolism, ecotoxicity, QSAR

Entactogens or empathogens are psychoactive substances that arouse a great interest of individuals who abuse these drugs but also the interest of health professionals, especially those who are involved in psychotherapy. Entactogens are used for both basic and clinical research, and experimental therapy, but also in recreational and psychospiritual settings where this practice is illicit or strictly regulated due to health concerns. Millions of people worldwide consume entactogens as recreational drugs at rave parties because they induce the feeling of euphoria, sharpened sensory perception and a greater capacity for social interactions (1).

\footnotetext{
*Correspondence, e-mail: mjadrijevic@pharma.hr
} 
The new therapeutic class under the term "entactogens" was proposed by Nichols based on unique human psychopharmacological effects of 3,4-methylendioxymethamphetamine (MDMA) and N-methyl-1(1,3-benzodioxol-5-yl)-2-butanamine (MBDB) which were distinct to hallucinogens (2).

In this class of psychoactive drugs, the MDMA (commonly known as "ecstasy", 'molly", "ADAM" or "XTC", etc.) is the prototypical entactogen molecule, the most famous and the first "designer drug" which became widely used despite being illegal, together with the related 3,4-methylendioxyamphetamine (MDA) (3). Pharmacologically, MDMA produces a specific and distinct extroverted mental state with experiences of emotional communion, oneness, relatedness, emotional openness, i.e., empathy or sympathy. MDMA was first synthesized in 1912 as an intermediate in the production of other chemical substance, however, in the latter part of the 20th century, it became the most widely studied and recreationally used entactogen, even though it was put on the list of Schedule I controlled substances in the USA in 1985 as a drug with a high potential of abuse $(4,5)$.

A unique profile of prosocial and interpersonal effects of entactogens is a consequence of the combination of catecholaminergic effects of methamphetamine, a precursor of MDMA, and the serotonergic effect of psychedelics. Evidence for the distinction of entactogens from both methamphetamine and psychedelics (Fig. 1) comes from structure-activity relationship (SAR) studies and animal models $(6,7)$.

Extensive literature search on the MDMA's mechanism of action (8-11) has come to characterize it as a drug with multiple mechanisms, that involve altering the activity of neurotransmitter amines in the brain, i.e., serotonin, dopamine and norepinephrine, but the final consensus is that the distinctive entactogenic effects arise primarily from the release of neurotransmitter serotonin which likely contributes to the recreational use (12-15).

Although marked as a drug with high abuse potential which impacted its clinical research in last decade of the 20th century, a growing body of evidence later indicates that

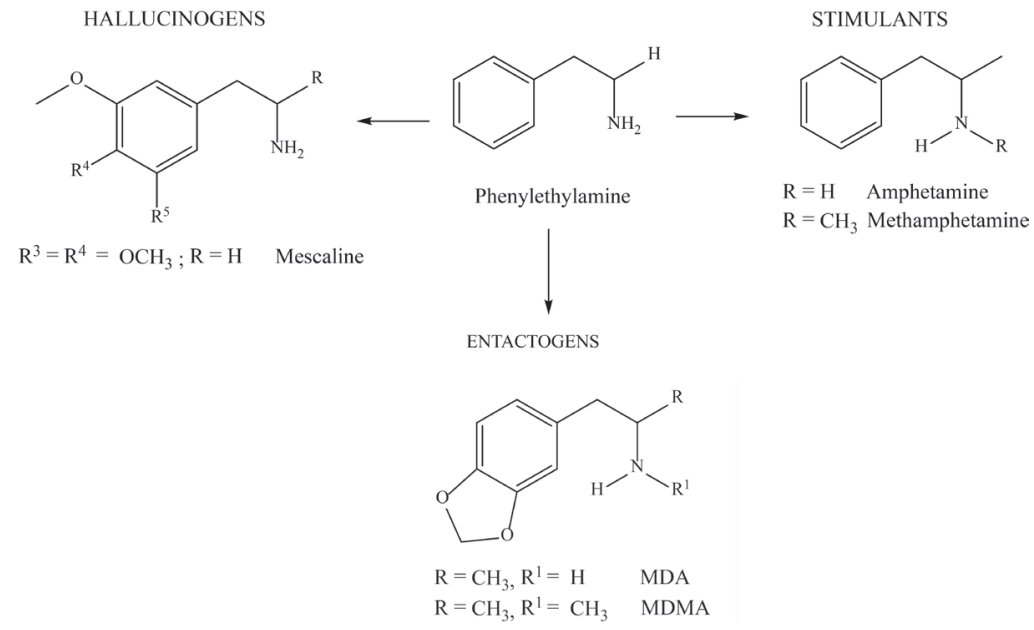

Fig. 1. Different phenylethylamine derivatives with hallucinogen (mescaline), stimulant (amphetamine and methamphetamine) and entactogen properties (MDA and MDMA) 
MDMA may have therapeutic applications $(6,16)$. To date, the most clinical MDMA research in patients has focused on MDMA-assisted psychotherapy for the treatment of posttraumatic stress disorder (PTSD) (17-19), whereas other potential applications include treatment of social anxiety in autism (20) and alcoholism-associated disorders (5), as well as the use in palliative care (21). After successful completion of Phase II trials, MDMA is included in Phase III of the drug development in 2018 with the set plan of licensing until 2021 for PTSD therapy by the FDA and EMA (22).

Since being introduced in many countries in the 1980s and despite the illegal status, MDMA pills became the most popular "street drug" and were often linked to rave and club parties where the misuse of MDMA and other illicit drugs at the same time has caused very often serious adverse reactions and fatal outcomes. Consequently, most of the efforts in the MDMA research were focused on its harmful effects (23-27).

The products sold on the illegal market as MDMA or "ecstasy", widely vary in the purity of the product and commonly contain adulterants that may, in fact, be another entactogen $(28,29)$. Thus, in the earliest period, the name "ecstasy" was a synonym for both MDA and MDEA, although the name "Eve" is more often used for MDEA by vendors and users. The MDMA, MDEA and MDA are structural analogues with closely related chemistry and biological effects, therefore, properties attributed to MDMA, mostly apply to MDEA, and to a significant extent to MDA (30).

Despite the abundance of literature data on the adverse effects of ecstasy, there is a widespread belief that ecstasy is a safe drug among teenagers and younger adults. However, "street drugs" that are very often sold under the name "ecstasy" may contain other known but undeclared entactogen or even new one that also has serious acute and chronic toxic side effects that resemble those previously seen with other amphetamines.

Serotonergic drugs (entactogens and hallucinogens) are associated with acute serotonin syndrome, hyperthermia, seizures, and hyponatremia (8). The ingestion and consequent toxicity of ecstasy misuse may result in serious or minor clinical symptoms depending on the individual patient, the dose administered, duration of the drug use, as well as the concomitant use of other drugs (22). Severe side-effects included sudden death, hyperpyrexia, rhabdomyolysis, multi-organ failure or isolated liver failure, serotonin syndrome, hyponatraemia with cerebral edema and acute panic disorder, whereas minor clinical symptoms were related to a disturbance in the central and autonomic nervous system such as tachycardia, hypertension, mydriasis, nystagmus, dry mouth, sweating, confusion, elevated mood and ataxia (23). Additionally, many other clinical symptoms and signs have been reported for regular ecstasy users e.g., intravascular coagulopathy, heart stroke, irritability, tremor, delirium, paranoia, depression, insomnia, loss of coordination and suicide (24-33). After the intake of usual recreational doses of 50 to $150 \mathrm{mg}$ of ecstasy, blood concentration varies between $100-250 \mathrm{ng} \mathrm{mL}^{-1}$ or $100-250 \mathrm{\mu g} \mathrm{L}^{-1}$, and in most cases of serious toxicity or fatality, blood concentrations ranged from 0.5 to $10 \mathrm{mg} \mathrm{L}^{-1}$ (30). Blood levels, such as low as $0.11-0.55$ $\mathrm{mg} \mathrm{L}^{-1}$, were also found in some intoxicated users, which almost overlapped recreational ranges, therefore other factors should also be taken into consideration of the seriousness of the effects, especially drug combinations and not only the concentration of ecstasy.

In the case of MDMA intoxication, there is no antidote (29), however, supportive care can be used. For example, in the control of agitation and anxiety or seizures, benzodiazepines may be administered, in the case of hyperthermia, rapid cooling is a priority, whereas, in the case of severe hypertension, an antihypertensive drug may be administered (23). 
Oral use of ecstasy is the most common way of ingestion, after which a rapid absorption into the bloodstream occurs, and effects begin 30-60 min lasting up to $8 \mathrm{~h}$ (30). MDMA has also been detected in toxicological analyses of a suspected drug-facilitated sexual assault (DFSA) (34). The misuse of illicit drugs causes indisputable societal damage and significantly increases health costs. Therefore, it is necessary to become well-informed with the usage levels and trends of these drugs in order to undertake the necessary actions to reduce this use. In several recent studies, it has been reported that illicit drugs are detectable in wastewater from municipal sewage treatment plants (STPs) and surface waters. This initiated a new developmental approach, i.e., sewage epidemiology, for the estimation of illicit drug use based on measurements of urinary-excreted illicit drugs and their metabolites in untreated wastewater (35). This is possible since, after the consumption, these substances are excreted in urine and feces unchanged or as active metabolites in high percentages and continuously discharged into domestic wastewaters. Residues of illicit drugs can, therefore, reach STPs in substantial amounts, escaping degradation, and are then released into surface waters. Found environmental concentrations are low, but the risk for human health and the environment cannot be excluded. Among illicit drugs, the morphine, cocaine, methamphetamine and ecstasy all have potent pharmacological activities and their presence in surface waters may be toxic to aquatic organisms (36).

The results of the study of MDMA load in sewage and wastewater treatment plants (WWTPs) in Paris and its suburban areas revealed that the mean MDMA consumption increases from 7.2 to $15.4 \mathrm{mg}$ day $^{-1}$ per young person between week and weekend and festive events (37). These values are rather low compared to findings in Italy, Spain, and the United Kingdom, countries with the highest consumption prevalence according to European Monitoring Centre for Drugs and Drug Addiction's (EMCDDA's). Thus, the most popular entactogens (MDA, MDMA and MDEA) were found in wastewater in north-eastern Spain in concentrations of 83,46 and $28 \mathrm{ng} \mathrm{L}^{-1}$, respectively, and the increase of ecstasy concentration per day (approximately 4 doses per 1000 young adults 15-34 years old) especially during the weekend, highlighted the illicit drug use as a new environmental problem with potential impact on aquatic ecosystems (38).

MDMA is not the same as „ecstasy" or "molly" because substances sold on the street under these names may contain MDMA, but they frequently also contain unknown and/or dangerous adulterants $(5,15)$. In laboratory studies, pure MDMA has been proven sufficiently safe for human consumption when taken a limited number of times in moderate doses. Unfortunately, the same cannot be concluded for all entactogen molecules that can be sold on the illegal market instead of MDMA with largely unknown properties.

The aim of this study was to predict the ADMET properties of selected entactogens of the phenylethylamine type and their $o$-quinones, the main metabolites mediated by cytochrome P450 enzymes, as well as to explore the relationship between molecular descriptors, ADMET properties and environmental toxicity parameters in order to highlight their impact on the environment and human health.

\section{MATERIALS AND METHODS}

The molecular descriptors (MDs) and ADMET parameters of investigated entactogens and their $o$-quinone-metabolites used in this in silico study were computed by ADMET Predictor $^{\mathrm{TM}}$ (Simulations Plus Inc., USA, www.simulations-plus.com) (39). The basic chemical 
structures of investigated entactogens and their $o$-quinone metabolites are displayed in Fig. 2 and in Table I, while 2D chemical structures, IUPAC names and SMILES (simplified molecular-input line-entry system) that were used for molecules entry input in the ADMET Predictor ${ }^{\mathrm{TM}}$ software of entactogen molecules and $o$-quinone metabolites are displayed in Supplementary material in Table S-1a and Table S-1b, respectively.

Statistical measurement and the prediction accuracy of ADMET Predictor's models used in this study are displayed in Table S-2 to Table S-5 in Supplementary Material.

ADMET-related descriptors relevant to environmental toxicity were computed using the following aquatic toxicity models:

1) TOX_FHM, the fathead minnow acute toxicity model based on lethal effects on Pimephales promelas (Minnow_LC $C_{50}$ ) which predicts concentration in $\mathrm{mg} \mathrm{L}^{-1}$ of a given compound that will kill $50 \%$ of a population of minnows after an exposure time of 96 hours (40);

2) TOX_ATTP model which is based on the inhibition of protozoa species Tetrahymena pyriformis and predicts concentration in $\mathrm{mmol} \mathrm{L}^{-1}$ of a given compound needed to inhibit $50 \%$ growth of $T$. pyroformis (Th_pyr_pIGC ${ }_{50}$ ) after approximately 40 hours exposure (41);

3) TOX_DM model which is based on lethal concentration $\left(\mathrm{mg} \mathrm{L}^{-1}\right)$ that results in the death of $50 \%$ of Daphnia magna (water fleas) (Daphnia $L C_{50}$ ) after 48 hours (42);

4) TOX_BCF model, the environmental toxicity based on bioconcentration factor (BCF) which is the ratio of the chemical concentration in biota to that in water at steady state, as a result of absorption via the respiratory surface, i.e., describes the accumulation of pollutants partitioning from the aqueous phase into an organic phase (typically fish), $\mathrm{BCF}=($ Concentration in organism $) /($ Concentration in environment $)(43)$ and

5) TOX_BIODEG model, the percent of biodegradation ( $\%$ BD $=100 \times$ BOD/ThOD) based on which a compound is considered readily biodegradable (RB) if the biological oxygen demand (BOD) is greater than or equal to $60 \%$ of the theoretical oxygen demand (ThOD), otherwise that compound is considered non-readily biodegradable (44).

The prediction accuracy and the statistical measurements of linear predictive models for the TOX_ATTP, TOX_FHM, TOX_DM and BCF are displayed in Table S-3 in Supplementary material while the validation of the binary predictive model of 2D TOX_BIODEG is displayed in Table S-4, also in Supplementary material.

The Metabolism module of ADMET Predictor ${ }^{\mathrm{TM}}(39,45)$, composed of CYP substrate/ non-substrate classification models for CYP enzymes 1A2, 2A6, 2B6, 2C8, 2C9, 2C19, 2D6, 2E1 and 3A4, their corresponding site of metabolism models (SOM) as well as kinetic parameter models $\left(K_{\mathrm{m}}, V_{\max }\right.$ and CLint) and CYP inhibition models for CYP1A2, 2C9, 2C19, 2D6, and

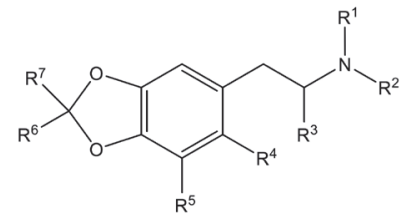<smiles>[R]C1=C(CC([R])N([R])C)C=CC(=O)C1[R]</smiles>

Fig. 2. The general formula of investigated entactogens (left) and their $o$-quinone metabolites (right), with the same substituents $\mathrm{R}$ to $\mathrm{R}^{5}$ listed in Table I. 
3A4 were used for the prediction of metabolite pathways of investigated entactogens. This prediction tool was trained on the Accelrys Metabolite Database. This data set has been curated and further sources for metabolic reactions were added. Models for the prediction of SOMs were based on artificial neural network ensembles (ANNEs) derived using atomic descriptors to generate an artificial neural network classification (ANNC) model. For each atom of a molecule, a score (0-1) for the likelihood of a metabolic reaction to happen was assigned. A substrate classification model can predict whether a compound is a substrate of five CYP enzymes.

Metabolites were generated using SMIRKS strings (a reaction transform language) to specify the transformations predicted by the SOM models. The CYP kinetic parameters were predicted from ANNE regression models. Statistical parameters for used toxicity and CYP metabolism binary predictive models of ADMET Predictor ${ }^{\mathrm{TM}}$ are displayed in Table S-5 in Supplementary Material.

All correlation analyses were performed using Origin Pro 8.0 software (Origin Laboratories, USA).

\section{RESULTS AND DISCUSSION}

In this in silico study, a set of 25 selected entactogen molecules (Table I) was investigated by the ADMET Predictor ${ }^{\mathrm{TM}}$ with the aim to evaluate their safety profile and potential impact on the environment and health. Although many in vitro and in vivo studies have been made on MDMA metabolism and its precursor MDA, and their Phase I as well as Phase II metabolites were fully characterized $(22,46-49)$, there are still limited available data about the metabolism of majority entactogens available on the illicit market. Therefore, in this study we explored ADMET properties of set of entactogens, including MDMA and its structural analogs $(N=25)$, as well as their $o$-quinone metabolites, with the aim to evaluate the potential environmental risk of these illicit drugs and to investigated the relationship between computed molecular descriptors (MDs), ADMET properties and related ecotoxicity parameters by QSAR studies. The molecular descriptors of parent entactogens (1-25) and their corresponding o-quinone metabolites (1-M1 to 25-M1) are displayed in Table II. The ADMET parameters of investigated entactogens and their $o$-quinone metabolites are summarized in Table III and Table IV, respectively. Data obtained for predicted CYP metabolic pathways of entactogens 1-25 with the involved CYP enzymes and the percentage of each metabolite are displayed in Table S-6-1 to Table S-6-3, while the comparative display of computed TOX_ Risks of investigated entactogens and their relative ecotoxicities, represented by pentagon plots, are displayed in Table S-7 in Supplementary Material.

\section{CYP metabolism - in silico approach}

The predicted CYP metabolism of investigated entactogen molecules involves two main pathways (Fig. 3, Table S-6-1 to Table S-6-3) analogous to those already observed and detected in vitro and in vivo studies of MDMA metabolism $(22,46-49)$.

The $O$-demethylenation represents the main pathway which was predicted for almost all investigated molecules (96\%) with exception of 1-(2,2-difluorobenzo[d][1,3]dioxol-5-yl) propan-2-amine (DiFMDA, 23) in which the 2,2-disubstitution enhanced the metabolic 
Tabl I. Investigated entactogens 1-25

\begin{tabular}{|c|c|c|c|c|c|c|c|c|c|}
\hline No. & Entactogen & $\mathrm{R}^{1}$ & $\mathrm{R}^{1}$ & $\mathrm{R}^{2}$ & $\mathrm{R}^{3}$ & $\mathrm{R}^{4}$ & $\mathrm{R}^{5}$ & $\mathrm{R}^{6}$ & $\mathrm{R}^{7}$ \\
\hline 1 & MDA & $\mathrm{H}$ & $\mathrm{H}$ & $\mathrm{H}$ & $\mathrm{CH}_{3}$ & $\mathrm{H}$ & $\mathrm{H}$ & $\mathrm{H}$ & $\mathrm{H}$ \\
\hline 2 & MDMA & $\mathrm{H}$ & $\mathrm{H}$ & $\mathrm{CH}_{3}$ & $\mathrm{CH}_{3}$ & $\mathrm{H}$ & $\mathrm{H}$ & $\mathrm{H}$ & $\mathrm{H}$ \\
\hline 3 & MDDM & $\mathrm{CH}_{3}$ & $\mathrm{CH}_{3}$ & $\mathrm{CH}_{3}$ & $\mathrm{CH}_{3}$ & $\mathrm{H}$ & $\mathrm{H}$ & $\mathrm{H}$ & $\mathrm{H}$ \\
\hline 4 & MDEA & $\mathrm{H}$ & $\mathrm{H}$ & $\mathrm{CH}_{2} \mathrm{CH}_{3}$ & $\mathrm{CH}_{3}$ & $\mathrm{H}$ & $\mathrm{H}$ & $\mathrm{H}$ & $\mathrm{H}$ \\
\hline 5 & MDPR & $\mathrm{H}$ & $\mathrm{H}$ & $\mathrm{CH}_{2} \mathrm{CH}_{2} \mathrm{CH}_{3}$ & $\mathrm{CH}_{3}$ & $\mathrm{H}$ & $\mathrm{H}$ & $\mathrm{H}$ & $\mathrm{H}$ \\
\hline 6 & MDBU & $\mathrm{H}$ & $\mathrm{H}$ & $\mathrm{CH}_{2} \mathrm{CH}_{2} \mathrm{CH}_{2} \mathrm{CH}_{3}$ & $\mathrm{CH}_{3}$ & $\mathrm{H}$ & $\mathrm{H}$ & $\mathrm{H}$ & $\mathrm{H}$ \\
\hline 7 & MDIP & $\mathrm{H}$ & $\mathrm{H}$ & $\mathrm{CH}\left(\mathrm{CH}_{3}\right) \mathrm{CH}_{3}$ & $\mathrm{CH}_{3}$ & $\mathrm{H}$ & $\mathrm{H}$ & $\mathrm{H}$ & $\mathrm{H}$ \\
\hline 8 & MDAL & $\mathrm{H}$ & $\mathrm{H}$ & $\mathrm{CH}_{2} \mathrm{CH}=\mathrm{CH}_{2}$ & $\mathrm{CH}_{3}$ & $\mathrm{H}$ & $\mathrm{H}$ & $\mathrm{H}$ & $\mathrm{H}$ \\
\hline 9 & MDPL & $\mathrm{H}$ & $\mathrm{H}$ & $\mathrm{CH}_{2} \mathrm{C} \equiv \mathrm{CH}$ & $\mathrm{CH}_{3}$ & $\mathrm{H}$ & $\mathrm{H}$ & $\mathrm{H}$ & $\mathrm{H}$ \\
\hline 10 & MDCPM & $\mathrm{H}$ & $\mathrm{H}$ & $\mathrm{CH}_{2}-\mathrm{C}_{3} \mathrm{H}_{5}{ }^{\mathrm{a}}$ & $\mathrm{CH}_{3}$ & $\mathrm{H}$ & $\mathrm{H}$ & $\mathrm{H}$ & $\mathrm{H}$ \\
\hline 11 & MDBZ & $\mathrm{H}$ & $\mathrm{H}$ & $\mathrm{CH}_{2} \mathrm{C}_{6} \mathrm{H}_{5}$ & $\mathrm{CH}_{3}$ & $\mathrm{H}$ & $\mathrm{H}$ & $\mathrm{H}$ & $\mathrm{H}$ \\
\hline 12 & $\mathrm{MDOH}$ & $\mathrm{H}$ & $\mathrm{H}$ & $\mathrm{OH}$ & $\mathrm{CH}_{3}$ & $\mathrm{H}$ & $\mathrm{H}$ & $\mathrm{H}$ & $\mathrm{H}$ \\
\hline 13 & MDHOET & $\mathrm{H}$ & $\mathrm{H}$ & $\mathrm{CH}_{2} \mathrm{CH}_{2} \mathrm{OH}$ & $\mathrm{CH}_{3}$ & $\mathrm{H}$ & $\mathrm{H}$ & $\mathrm{H}$ & $\mathrm{H}$ \\
\hline 14 & MDMEO & $\mathrm{H}$ & $\mathrm{H}$ & $\mathrm{OCH}_{3}$ & $\mathrm{CH}_{3}$ & $\mathrm{H}$ & $\mathrm{H}$ & $\mathrm{H}$ & $\mathrm{H}$ \\
\hline 15 & MDMEOET & $\mathrm{H}$ & $\mathrm{H}$ & $\mathrm{CH}_{2} \mathrm{CH}_{2} \mathrm{OCH}_{3}$ & $\mathrm{CH}_{3}$ & $\mathrm{H}$ & $\mathrm{H}$ & $\mathrm{H}$ & $\mathrm{H}$ \\
\hline 16 & $\mathrm{BDB}$ & $\mathrm{H}$ & $\mathrm{H}$ & $\mathrm{H}$ & $\mathrm{CH}_{2} \mathrm{CH}_{3}$ & $\mathrm{H}$ & $\mathrm{H}$ & $\mathrm{H}$ & $\mathrm{H}$ \\
\hline 17 & MBDB & $\mathrm{H}$ & $\mathrm{H}$ & $\mathrm{CH}_{3}$ & $\mathrm{CH}_{2} \mathrm{CH}_{3}$ & $\mathrm{H}$ & $\mathrm{H}$ & $\mathrm{H}$ & $\mathrm{H}$ \\
\hline 18 & Ethyl-K & $\mathrm{H}$ & $\mathrm{H}$ & $\mathrm{CH}_{2} \mathrm{CH}_{3}$ & $\mathrm{CH}_{2} \mathrm{CH}_{2} \mathrm{CH}_{3}$ & $\mathrm{H}$ & $\mathrm{H}$ & $\mathrm{H}$ & $\mathrm{H}$ \\
\hline 19 & 5-MeMDA & $\mathrm{H}$ & $\mathrm{H}$ & $\mathrm{H}$ & $\mathrm{CH}_{3}$ & $\mathrm{H}$ & $\mathrm{CH}_{3}$ & $\mathrm{H}$ & $\mathrm{H}$ \\
\hline 20 & MMDA & $\mathrm{H}$ & $\mathrm{H}$ & $\mathrm{H}$ & $\mathrm{CH}_{3}$ & $\mathrm{H}$ & $\mathrm{OCH}_{3}$ & $\mathrm{H}$ & $\mathrm{H}$ \\
\hline 21 & MMDA-2 & $\mathrm{H}$ & $\mathrm{H}$ & $\mathrm{H}$ & $\mathrm{CH}_{3}$ & $\mathrm{OCH}_{3}$ & $\mathrm{H}$ & $\mathrm{H}$ & $\mathrm{H}$ \\
\hline 22 & MMDPEA & $\mathrm{H}$ & $\mathrm{H}$ & $\mathrm{H}$ & $\mathrm{H}$ & $\mathrm{H}$ & $\mathrm{OCH}_{3}$ & $\mathrm{H}$ & $\mathrm{H}$ \\
\hline 23 & DiFMDA & $\mathrm{H}$ & $\mathrm{H}$ & $\mathrm{H}$ & $\mathrm{CH}_{3}$ & $\mathrm{H}$ & $\mathrm{H}$ & F & $\mathrm{F}$ \\
\hline 24 & EIDA & $\mathrm{H}$ & $\mathrm{H}$ & $\mathrm{H}$ & $\mathrm{CH}_{3}$ & $\mathrm{H}$ & $\mathrm{H}$ & $\mathrm{CH}_{3}$ & $\mathrm{H}$ \\
\hline 25 & 2,3-MDA & $\mathrm{H}$ & $\mathrm{H}$ & $\mathrm{H}$ & $\mathrm{CH}_{3}$ & $\mathrm{H}$ & $\mathrm{H}$ & $\mathrm{H}$ & $\mathrm{H}$ \\
\hline
\end{tabular}

${ }^{\text {a }} \mathrm{CH}_{2}$-cyclopropyl

stability of this drug (50). For this metabolic reaction the main cytochrome P450 enzymes, i.e., CYP1A2 and 2D6 were predicted with the highest probability, however, CYP2C9, 2C19 and 3A4 were also predicted, but to significantly less extent (Table S-6-1).

As the CYP2D6 represents one of the major catalyzing enzymes in this reaction, and since it is an enzyme which is characterized by genetic polymorphism in humans, this metabolic reaction might be of higher risk for acute entactogen's toxicity in slow metabolizers (23, 49). The risk of polymorphism may be diminished by the formation of an auto-inhibiting enzyme-metabolite complex and auto-inhibition which renders this toxicity in all subjects, regardless of genotype, and the limited effect of CYP2D6 pharmacogenetic variation on the acute toxicity was also observed in previous pharmacokinetic studies of MDMA (31). 


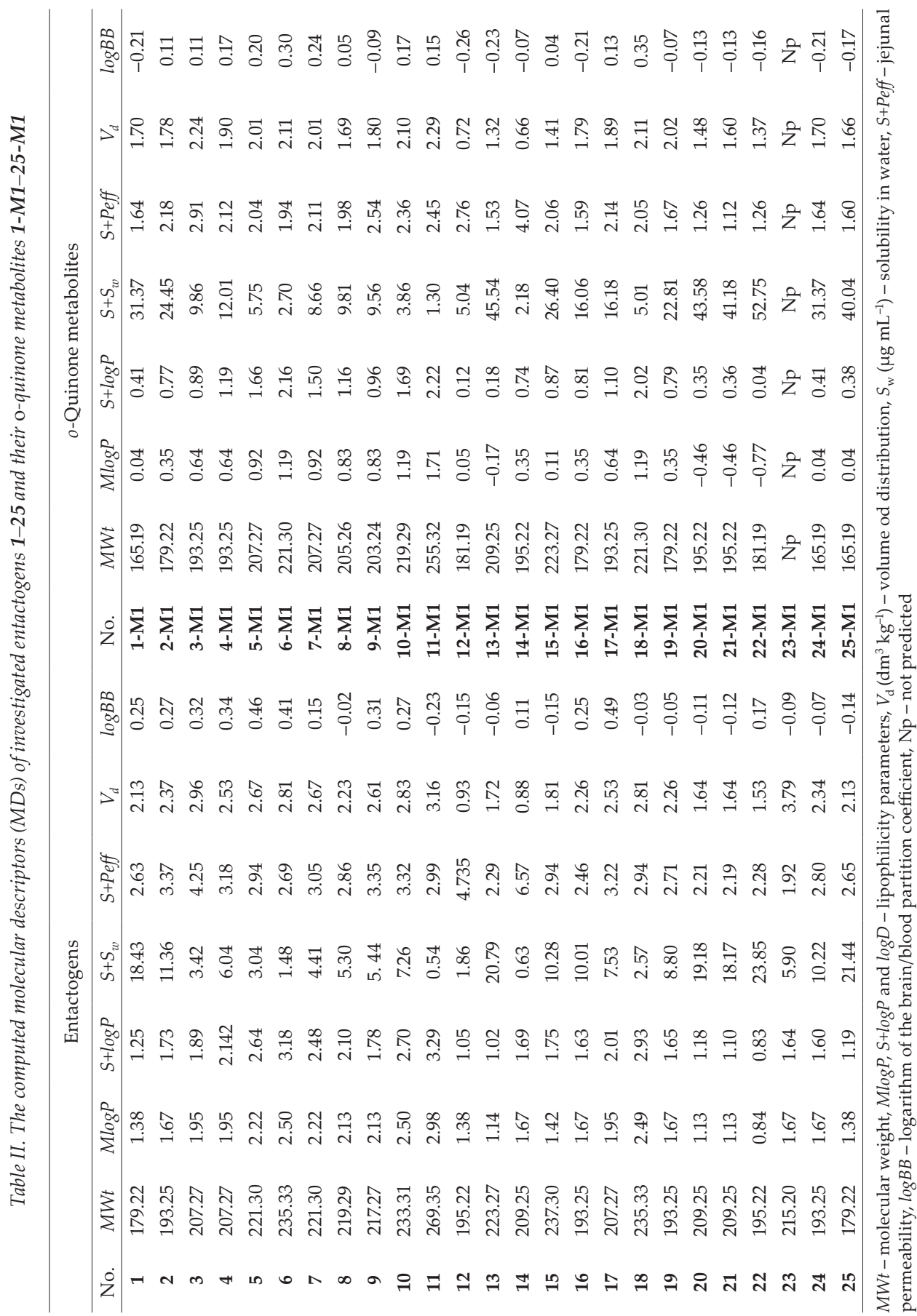




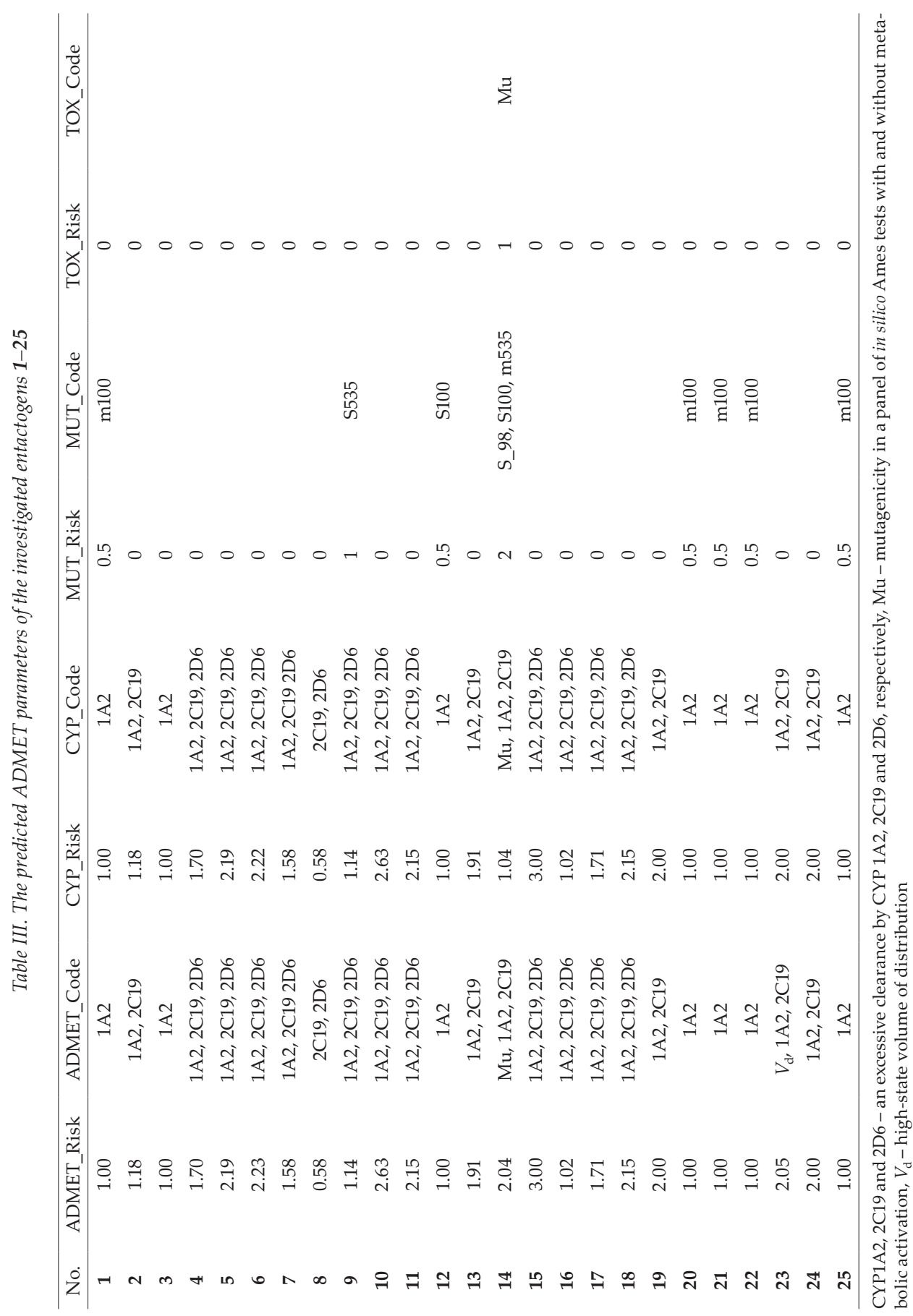


Table IV. The predicted ADMET parameters of the o-quinone metabolites 1-M1-25-M1

\begin{tabular}{|c|c|c|c|c|c|c|c|c|c|}
\hline No. & $\begin{array}{c}\text { ADMET_ }_{\text {Risk }} \\
\text { Ris }\end{array}$ & $\begin{array}{c}\mathrm{ADMET}_{-} \\
\text {Code }\end{array}$ & $\begin{array}{l}\text { CYP_ } \\
\text { Risk }\end{array}$ & $\begin{array}{l}\mathrm{CYP}_{-} \\
\text {Code }\end{array}$ & $\begin{array}{c}\text { MUT_ } \\
\text { Risk }\end{array}$ & $\begin{array}{c}\mathrm{MUT}_{-} \\
\text {Code }\end{array}$ & $\begin{array}{l}\text { TOX_- } \\
\text { Risk }\end{array}$ & $\begin{array}{l}\text { TOX_- } \\
\text { Code }\end{array}$ & $\begin{array}{c}\text { Percent of } \\
\text { predicted } \\
\text { o-quinone } \\
\text { metabolites }\end{array}$ \\
\hline 1-M1 & 1 & $\mathrm{mi}$ & 1 & $\mathrm{mi}$ & 0 & & 0 & & 36 \\
\hline 2-M1 & 0.12 & $1 \mathrm{~A} 2$ & 0.12 & $1 \mathrm{~A} 2$ & 0 & & 0 & & 24 \\
\hline 3-M1 & 0.84 & $1 \mathrm{~A} 2, \mathrm{mi}$ & 0.84 & $1 \mathrm{~A} 2, \mathrm{mi}$ & 0 & & 0 & & 31 \\
\hline 4-M1 & 1 & $\mathrm{Hp}$ & 0 & & 0 & & 1 & Hp & 42 \\
\hline 5-M1 & 0 & & 0 & & 0 & & 0 & & 52 \\
\hline 6-M1a & 0 & & 0 & & 0 & & 0 & & 48 \\
\hline 7-M1 & 0 & & 0 & & 0 & & 0 & & 43 \\
\hline 8-M1 & 0 & & 0 & & 0 & & 0 & & 68 \\
\hline 9-M1 & 0 & & 0 & & 1 & S535 & 0 & & 45 \\
\hline 10-M1 & 0.52 & 2D6 & 0.52 & 2D6 & 1 & S_97 & 0 & & 62 \\
\hline 11-M1 & 1 & 2D6 & 1 & 2D6 & 0 & & 0 & & 52 \\
\hline 12-M1 & 1 & $\mathrm{Mu}$ & 0 & & 1.5 & S_97, S100 & 1 & $\mathrm{Mu}$ & 36 \\
\hline 13-M1 & 0 & & 0 & & 0 & & 0 & & 31 \\
\hline 14-M1 & 3 & $\mathrm{Hp}, \mathrm{Mu}, 1 \mathrm{~A} 2$ & 1 & $1 \mathrm{~A} 2$ & 1.5 & S100, m535 & 2 & $\mathrm{Hp}, \mathrm{Mu}$ & 36 \\
\hline 15-M1 & 0 & & 0 & & 0 & & 0 & & 26 \\
\hline 16-M1 & 1 & $\mathrm{mi}$ & 1 & $\mathrm{mi}$ & 0 & & 0 & & 56 \\
\hline 17-M1 & 1 & Hp & 0 & & 0 & & 1 & Hp & 36 \\
\hline 18-M1 & 1 & Hp & 0 & & 0 & & 1 & Нp & 60 \\
\hline 19-M1 & 1 & $\mathrm{mi}$ & 1 & $\mathrm{mi}$ & 0 & & 0 & & 39 \\
\hline 20-M1 & 0 & & 0 & & 0 & & 0 & & 9 \\
\hline 21-M1 & 0 & & 0 & & 0 & & 0 & & 19 \\
\hline 22-M1 & 0 & & 0 & & 0 & & 0 & & 12 \\
\hline 23-M1 & $\mathrm{Np}$ & $\mathrm{Np}$ & $\mathrm{Np}$ & $\mathrm{Np}$ & $\mathrm{Np}$ & $\mathrm{Np}$ & $\mathrm{Np}$ & $\mathrm{Np}$ & - \\
\hline 24-M1 & 1 & $\mathrm{mi}$ & 1 & $\mathrm{mi}$ & 0 & & 0 & & 15 \\
\hline 25-M1 & 1 & $\mathrm{mi}$ & 1 & $\mathrm{mi}$ & 0 & & 0 & & 28 \\
\hline
\end{tabular}

mi - midazolam inhibition, Hp - hepatotoxicity, Mu - mutagenicity, 1A2 and 2D6 - CYP 1A2 and CYP 2D6, S_97, $\mathrm{S} 100, \mathrm{~S} 535$ af m535 - predicted mutagenicity, $\mathrm{Np}$ - not predicted

By further oxidation steps, the formed O-demethylenated metabolites produced $o$-quinone metabolites in all studied entactogens except for DiFMDA (23). These metabolites were predicted in the yields ranging from 15 to $68 \%$ (Table IV, Table S-6-1).

The other important pathways that correspond to oxidative $\mathrm{N}$ - or $\mathrm{O}$-dealkylation to corresponding amine or hydroxylamine metabolites were predicted for 18 entactogens (72 $\%)$, i.e., 2-11, 13-15, 17, 18, 20, 24 and 25). Both these reactions were catalyzed by almost the same enzymes, i.e., CYP1A2 and 2D6 with higher probability, and also by CYP2C9, 2C19 and 3A4, however with significantly less extent.

The oxidative deamination to corresponding carbonyl metabolites was predicted for 10 entactogens $(40 \%$, i.e., $\mathbf{1}, \mathbf{2}, \mathbf{1 2}, \mathbf{1 6}, \mathbf{1 9 - 2 5})$ while the $N$-hydroxylation of formed amines to 


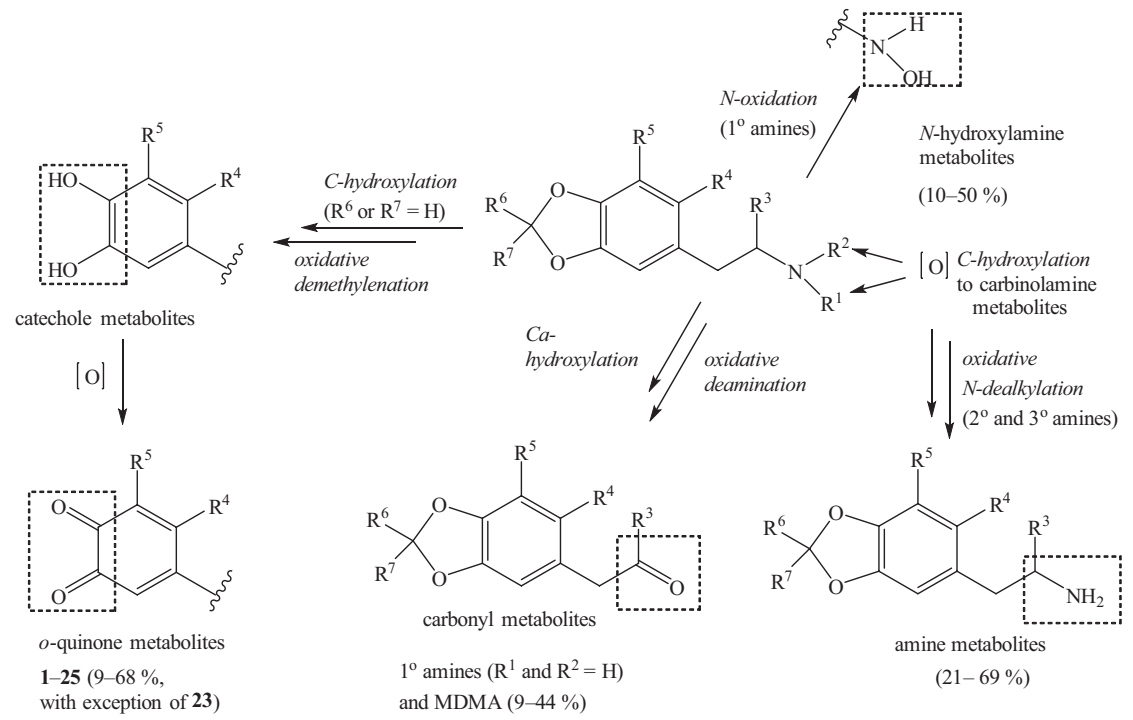

Fig. 3. Predicted biotransformation pathways of investigated entactogens 1-25 mediated by CYP enzymes using Simulations Plus ${ }^{\mathrm{TM}}$ Metabolite module.

corresponding hydroxylamine metabolites were predicted in metabolic pathways of the six entactogens (24\%, i.e., 1, 19-23) (Fig. 3, Table S-6-1).

All other pathways that involve either hydroxylation of alkyl chain $(5,6,10,15,19,20$, 22-25, Table S-6-2) or aromatic moiety $(\mathbf{1 1}, \mathbf{1 3}, \mathbf{1 9 - 2 2}$ in Table S-6-3) or oxidation of already formed hydroxylamine (12, Table S-6-3) were specific for particular entactogen and were predicted mostly to less extent as minor metabolites.

As expected, the lipophilicity $(M \log P)$ computed according to the method by Moriguchi et al. (53), the parent entactogen molecules were revealed as more lipophilic (MlogP 0.84-2.98) in comparison to their corresponding o-quinone metabolites (MlogP 0.04-2.22). The same was revealed for other lipophilicity parameters, i.e., $S+\log P$ and $\log B B$ (the $\log$ arithm of the brain/blood partition coefficient) (Table II). The opposite was found for $o$-quinone metabolites in terms of their water solubility $\left(S+S_{w}\right)$ for which the predicted scores were almost doubled, i.e., with the $S+S_{w}$ in the range from 1.30 (11-M1) to 52.85 (22-M1) while for their parent molecules $S+S_{\mathrm{w}}$ was computed in the range from 0.54 (11) to 23.85 (22) (Table II).

Prediction of the tissue distribution of investigated entactogen molecules is important not only in the drug development but also in the evaluation of toxicokinetics, therefore the volume of distribution $\left(V_{\mathrm{d}}\right)$ and the descriptors describing the blood-brain barrier (BBB) penetration such as $\log B B$ are valuable in the evaluation of these drugs (51). The investigated entactogens possess volume of distribution $\left(V_{\mathrm{d}} / \mathrm{dm}^{3} \mathrm{~kg}^{-1}\right)$ in the range of $0.88-3.77 \mathrm{dm}^{3} \mathrm{~kg}^{-1}$ and the highest value was computed for DiFDMA (23) what was revealed as one of the ADMET risks for this entactogen, and the lowest for MDMEO (14) in a set of parent entactogens. In a set of $o$-quinone metabolites, the $V_{\mathrm{d}}$ was ranged from 0.66 (14-M1) to $2.29 \mathrm{dm}^{3} \mathrm{~kg}^{-1}$ (11-M1).

The logarithm of the blood-brain partition coefficient $(\log B B)$ were computed for the entactogen molecules in the range $\log B B$ from -0.23 to 0.49 with the lowest value computed 
for $\mathrm{MDOH}$ (12) and the highest for $\mathrm{MBDB}$ (17), while for $o$-quinone metabolites this parameter was computed from -0.26 to 0.35 with the lowest value predicted for $o$-quinone of MDOH (12-M1) and the highest for $o$-quinone metabolite of Ethyl-K (18-M1). The jejunal permeability, $S+P e f f$ were computed in the range from 1.92 (23) to 6.57 (14) in a set of parent entactogen molecules, while in the set of $o$-quinone metabolites, the S+Peff ranged from 1.12 (21-M1) to 4.07 (14-M1).

All three parameters $\left(S+P e f f, \log B B\right.$ and $\left.V_{\mathrm{d}}\right)$ were somewhat lesser in the set of $o$-quinone metabolites than in the set of parent entactogens.

\section{ADMET analysis}

The main purpose of the in silico predictions of ADMET properties of compounds is the prediction of their in vivo biokinetics (54) since a good ADMET profile of a drug is necessary as a good biological property of that drug. In order to predict ADMET properties of the investigated entactogens and their $o$-quinone metabolites, we used the ADMET Predictor ${ }^{\mathrm{TM}}$.

In order to explore if there are excessive ADMET disadvantages for these molecules, the ADMET Risk module was applied. The predicted ADMET properties of investigated entactogen molecules (1-25) (Table III) were compared with their corresponding o-quinone metabolites 1-M1 to 25-M1, with exception of the $o$-quinone metabolite of $\mathbf{2 3}$ that was not predicted (Table IV).

The ADMET_Risk, a measure that corresponds to overall risk due to absorption, distribution, metabolism and excretion, was ranged from 0.48 (8) to 3.00 (15) (Table III) for entactogen molecules, whereas for $o$-quinone metabolites it ranged from $0.00(\mathbf{5}-\mathbf{9}, \mathbf{1 3}, \mathbf{1 5}, \mathbf{2 0}-\mathbf{2 2})$ to 3.00 (14) (Table IV). For comparison, ADMET Risk is larger than 6.5 for about $10 \%$ of the drugs comprised in World Drug Index (WDI) in which $10 \%$ of drugs violate more than six of the default rules (39).

Toxicity was estimated by two ADMET risk models: TOX_MUT Risk and TOX_Risk module. TOX_MUT Risk is a summary of the outputs of the ten different TOX_MUT models that independently predict the mutagenicity expected for five strains of $S$. typhimurium with and without microsomal activation. The TOX_Risk model consists of seven rules of different toxicities.

The mutagenicity $(\mathrm{Mu})$ was predicted for MDMEO (14) and $o$-quinone metabolites of $\mathrm{MDOH}$ (12-M1) and MDMEO (14-M1), whereas the hepatotoxicity (Hp) was predicted in the set of $o$-quinones for the MDEA (4-M1), MDMEO (14-M1), MBDB (17-M1) and Ethyl-K (18-M1).

In addition to the mutagenicity $(\mathrm{Mu})$ and hepatotoxicity $(\mathrm{Hp})$, the clearance of cytochrome P450 catalyzing enzymes, i.e., CYP1A2, 2C19, and 2D6 was also revealed as CYP risks in a set of entactogens (Table III), whereas in a set of $o$-quinone metabolites in addition to $\mathrm{Mu}$ and $\mathrm{Hp}$ the CYP risk due to clearance of $1 \mathrm{~A} 2$ and the midazolam inhibition (mi) for $\mathbf{1}$, $3,16,19,24$ and 25 were revealed.

Among the investigated entactogen molecules, the MDMEO (14) was revealed as the molecule with the worst predicted safety profile (Fig. 4), since the mutagenicity (Mu) was predicted for both, parent entactogen MDMEO (14) and its o-quinone metabolite (14-M1), and both molecules can be metabolized to $o$-quinone 12-M1 for which mutagenicity was also predicted. For the $o$-quinone metabolite 14-M1 the hepatotoxicity (Hp) has also been predicted. 

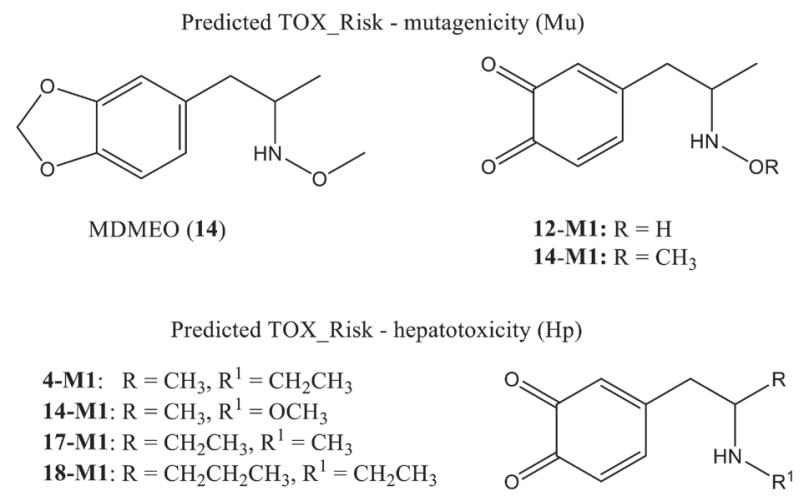

Fig. 4. Entactogen molecule MDMEO (14), and its o-quinone metabolite of MDMEO (14-M1) and the $o$-quinone metabolite of MDOH (12-M1) for which the mutagenicity $(\mathrm{Mu})$ has been predicted and $o$ quinones of MDEA (4-M1), MDMEO (14-M1), MBDB (17-M1) and Ethyl-K (18-M1) for which the hepatotoxicity $(\mathrm{Hp})$ has been predicted.

\section{Environmental toxicity evaluation - in silico approach}

The results of models useful for the evaluation of environmental toxicity, i.e., the acute toxicity in Tetrahymena pyriformis (TOX_ATTP expressed as Th_pyr_pIGC s0 $_{0}$ in $\mathrm{mmol} \mathrm{L}^{-1}$ ), the acute toxicity in Pimephales promelas, the fathead minnow (TOX_FHM expressed as Minnow $L C_{50}$ in $\mathrm{mg} \mathrm{L}^{-1}$ ) and the acute toxicity in Daphnia magna (TOX_DM expressed as Daphnia_LC $C_{50}$ in $\mathrm{mg} \mathrm{L}^{-1}$ ) as well as bioconcentration factor (BCF) and biodegradability (TOX_Biodeg) of entactogen molecules (1-25) and corresponding $o$-quinone metabolites (1-M1-25-M1) are displayed in Table V. The investigated entactogens 1-25 were revealed as non-biodegradable molecules (estimated Biodegradn - No $96 \%$ ) while the majority of their $o$-quinone metabolites (1-M1-18-M1, 22-M1 and 24-M1) were predicted as biodegradable (Yes 58-87 \%) with the exception of o-quinones 19-M1-21-M1, 23-M1 and 25-M1. Likelihood of a chemical's biodegradation in the environment for investigated entactogens and their metabolites was predicted based on quantitative structure-biodegradability relationship (QSBR) models, the combinatorial classification probability models of ready biodegradability (RB) versus not ready biodegradability (NRB) of chemicals that are based on the largest Japanese MITI data set (52).

The predicted scores for bioconcentration factor $(\mathrm{BCF})$ of the investigated entactogens were computed in the range from 4.64 to 68.66, while for their $o$-quinones were computed in the range from 1.66 to 3.23 . These findings imply the conclusion that the accumulation of $o$-quinone metabolites, will be with lesser partitioning between the aqueous phase and the organic phase (typically fish) in comparison to their parent entactogens.

The acute environmental toxicities were computed as follows:

a) for entactogens the TOX_FHM in the range from 2.65 (11) to 172.27 (13) $\mathrm{mg} \mathrm{L}^{-1}$, TOX_ATPP from -0.62 (18) to 1.17 (11) $\mathrm{mmol} \mathrm{L}^{-1}$ and TOX_DM from 0.60 (9) to 29.11 (3) $\mathrm{mg} \mathrm{L}^{-1}$,

b) for $o$-quinone metabolites the TOX_FHM in the range from 0.21 (8-M1) to 2.30 (22M1) mg L ${ }^{-1}$, TOX_ATPP from -0.83 (13-M1) to 0.45 (11-M1) $\mathrm{mmol} \mathrm{L}^{-1}$ and TOX_DM from 0.95 (9-M1) to 177.98 .11 (3-M1) $\mathrm{mg} \mathrm{L}^{-1}$. 


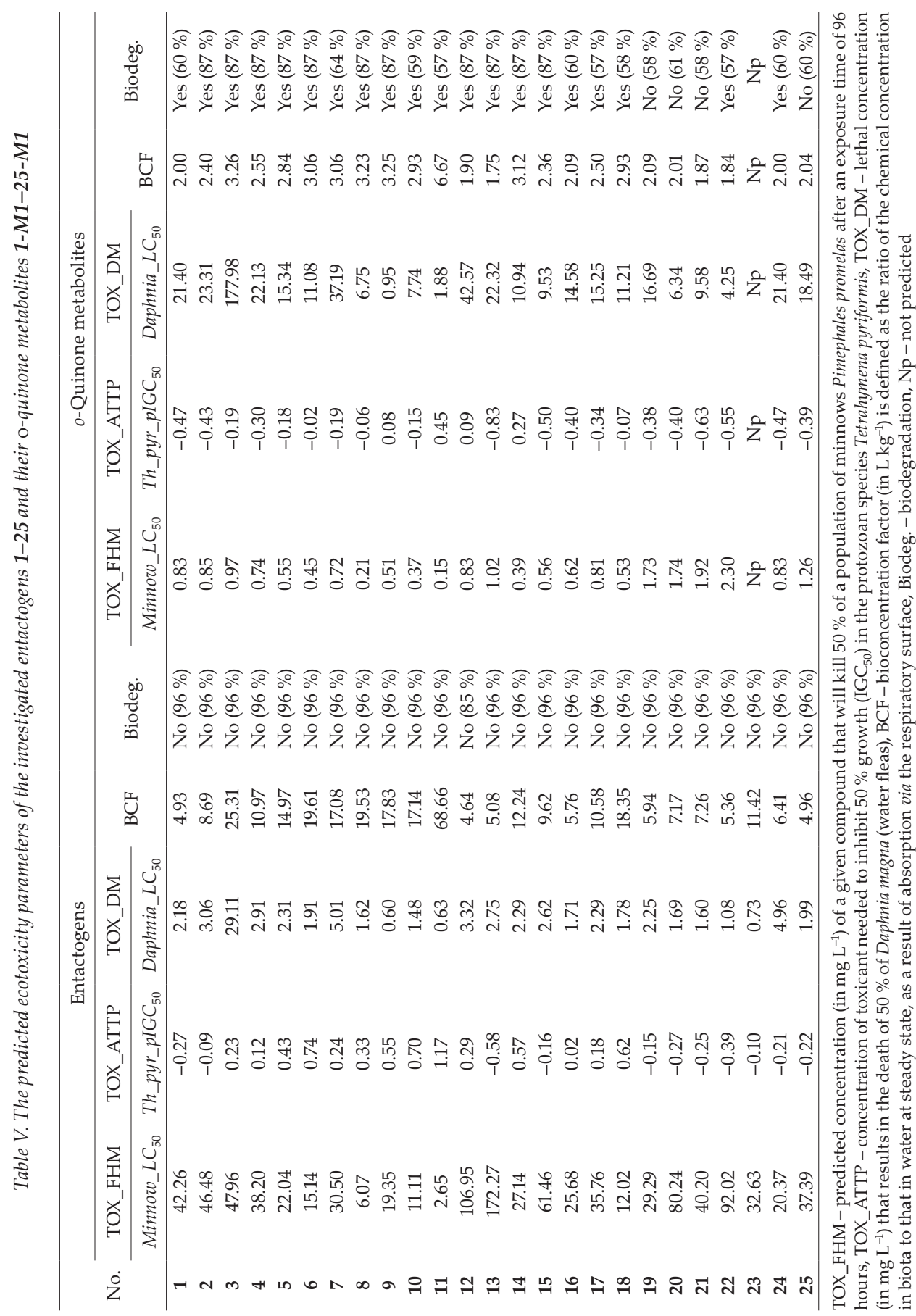


Based on the predicted biodegradability as well as the obtained computed scores for TOX_FHM, TOX_ATTP, TOX_DM and TOX BCF for the set of entactogen molecules 1-25 and the set of their $o$-quinone metabolites (1-M1 to 25-M1), it can be concluded that $o$-quinone metabolites are more ecotoxic comparing to their parent entactogens.

\section{Quantitative structure activity relationship (QSAR)}

The computed molecular descriptors (MDs), ADMET properties and parameters relevant to environmental toxicity were used in this QSAR study. The best correlations were obtained with $M \log P$ which was computed in the range between 0.84 and 2.98 for entactogen molecules and for corresponding o-quinone metabolites $M \log P$ was computed in the range from -0.77 to -1.71 . The relationship between lipophilicity $M \log P$ of entactogens is

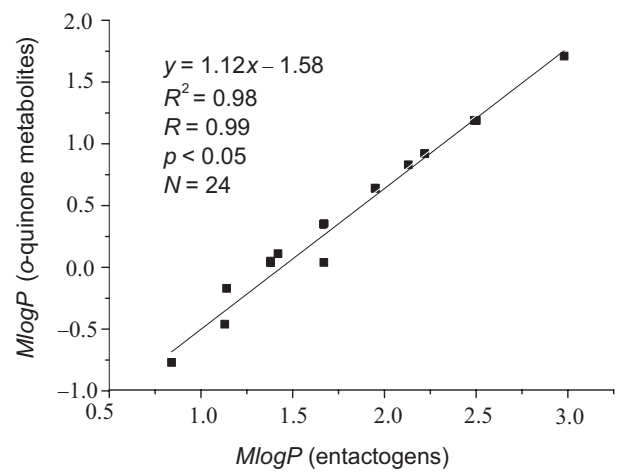

Fig. 5. The relationship of the $M \log P$ of entactogens (with exception of 23) and $M \log P$ of $o$-quinone metabolites.

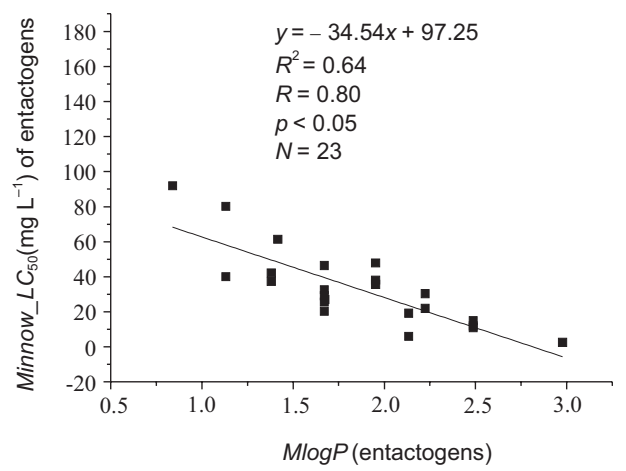

Fig. 7. The relationship of the $M \log P$ of entactogens (12 and 13 excluded) and their predicted toxicity against fathead minnow expressed as Minnow_LC ${ }_{50}\left(\mathrm{mg} \mathrm{L}^{-1}\right)$.

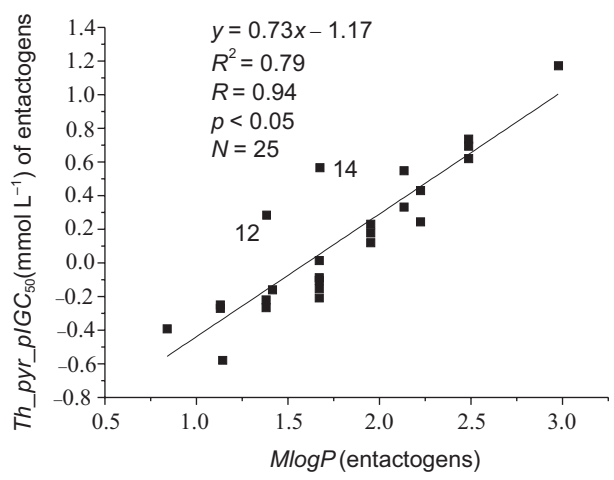

Fig. 6. The relationship of the $M \log P$ of entactogens and their toxicity against $T$. pyriformis expressed as Th_pyr_pIGC $C_{50}\left(\mathrm{mmol} \mathrm{L}^{-1}\right)$.

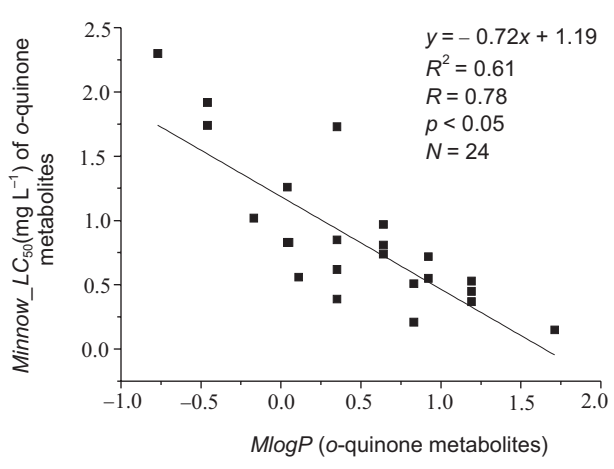

Fig. 8. The relationship of the $M \log P$ of $o$-quinone metabolites and their predicted toxicity against fathead minnow expressed as Minnow_LC $C_{50}(\mathrm{mg}$ $\mathrm{L}^{-1}$ ). 


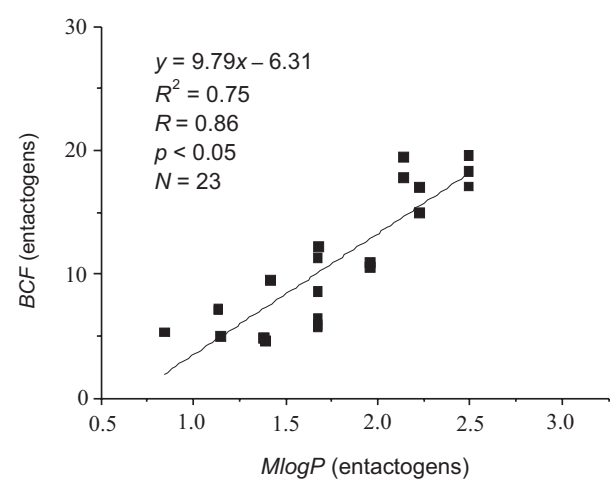

Fig. 9. The relationship of the $M \log P$ of entactogens ( 3 and $\mathbf{1 1}$ excluded) and their bioconcentration factors $(B C F)$.

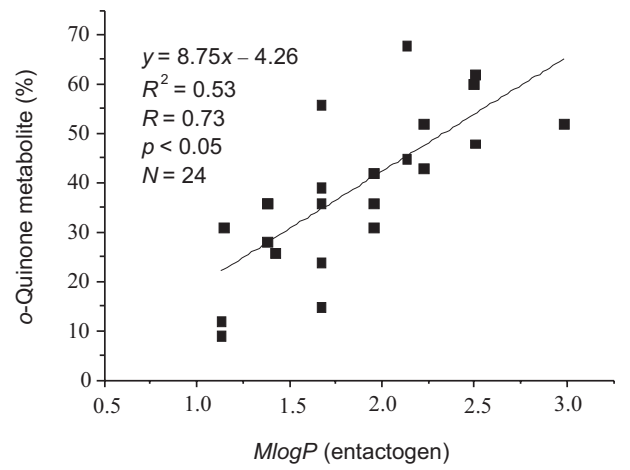

Fig. 11. The relationship of the $M \log P$ of entactogens (with exception of 23) and the percentage (\%) of $o$-quinone metabolites' yields.

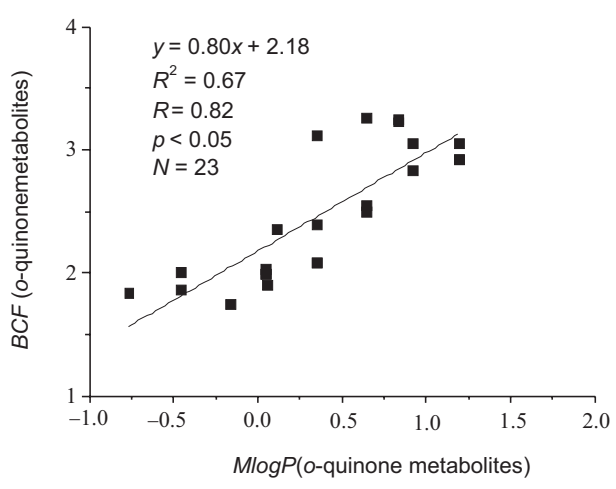

Fig. 10. The relationship of the $M \log P$ and the bioconcentration factors $(B C F)$ of $o$-quinone metabolites.

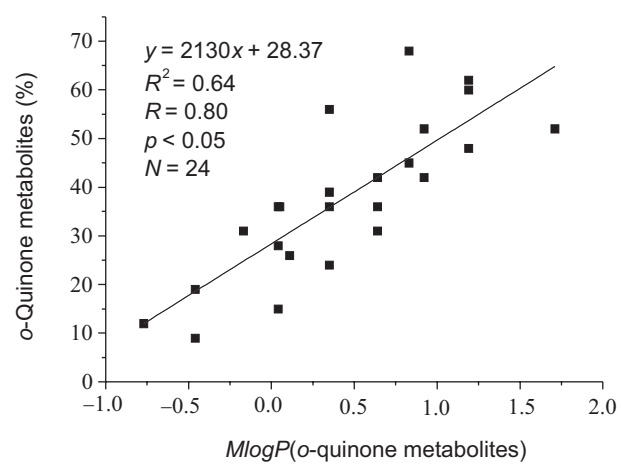

Fig. 12. The relationship of the $M \log P$ and the percentage (\%) of $o$-quinone metabolites' yields.

in a significant linear correlation with the $M \log P$ of their corresponding $o$-quinone metabolites $(R=0.99)$ (Fig. 5).

A significant linear correlation $(R=0.94)$ obtained between $M \log P$ of entactogens against TOX_ATTP expressed as Th_pyr_pIGC ${ }_{50}$ (the lethal concentration that results in the death of $50 \%$ of protozoa species Tetrahymena pyriformis) is displayed in Fig. 6. The highest Th_pyr_ $p I G C_{50}$ scores were obtained for $N$-(1-(benzo[d][1,3]dioxol-5-yl)propan-2-yl)hydroxyl-amine (MDOH, 12) and $N$-(1-(benzo[d][1,3]dioxol-5-yl)propan-2-yl)-O-methylhydroxylamine (MDMEO, 14), which might suggest that the presence of $\mathrm{N}-\mathrm{O}$ bond in the entactogen structure reduces toxicity against $T$. pyriformis as was the case with increase of lipophilicity.

QSAR studies also revealed a significant linear correlation between MlogP and TOX_ FHM expressed as Minnow_LC $C_{50}$ computed for entactogens and $o$-quinone metabolite (Fig. 7 and Fig. 8, respectively). One can observe that, with the increase of lipophilicity, either in the set of entactogens or in the set of their $o$-quinone metabolites, the toxicities against 
fathead minnow also increase, and o-quinone metabolites showed to be more toxic because they can produce the same lethal effect in smaller concentrations.

Linear relationships were also observed between $M \log P$ and bioconcentration factors (BCFs) of entactogens and BCFs of their $o$-quinone metabolites (Fig. 9 and Fig. 10, respectively). The risk of bioconcentration factor (BCF) increases with the increase either with lipophilicity of entactogens or $o$-quinone metabolites.

Although, with somewhat lesser coefficient correlations, the linear relationships were also found between $M \log P$ either of entactogens or $M \log P$ of their corresponding $o$-quinone metabolites with the predicted percentage of $o$-quinone metabolites' yields.

No significant correlations were found between $M \log P$ and TOX_DM expressed as Daphnia $L_{50}$.

Statistical data of the linear correlations and linear fit obtained by OriginPro8 between $M \log P$ and ecotoxic and other parameters of investigated entactogens and their corresponding o-quinone metabolites are displayed in Table VI.

\section{CONCLUSIONS}

Many toxicants, including drugs, are present in our environment, and in the case of lack of their toxic data, the in silico methods of toxicokinetics can provide useful information for integration chemical toxicity and exposure estimation in order to predict potential chemical, biochemical and environmental risks. In this in silico study, a set of 25 selected entactogen molecules and their corresponding $o$-quinone metabolites were analyzed by the ADMET Predictor ${ }^{\mathrm{TM}}$ software with the aim to evaluate their ADMET profile and potential risk impact on the environment and consequently on human health.

For many of entactogens included in this study, there are limited available data on their metabolism and their potential environmental risks.

The evaluated entactogens have been revealed as non-biodegradable molecules while the majority of their corresponding $o$-quinones were revealed as biodegradable metabolites.

In silico study of CYP-metabolism of the investigated entactogens was characterized by two main metabolic pathways analogous to those already observed and detected in vitro and in vivo studies of MDMA metabolism. The first pathway is $O$-demethylenation which was predicted for almost all investigated molecules $(96 \%)$ with an exception of 1-(2,2-difluorobenzo[d][1,3]dioxol-5-yl)propan-2-amine (DiFMDA, 23) in which the 2,2-disubstitution enhanced the metabolic stability of this drug.

For this reaction the main cytochrome P450 enzymes CYP1A2 and 2D6 were predicted with the highest probability, however, CYP2C9, 2C19 and 3A4 were also predicted, but to a significantly less extent. The $O$-demethylenated metabolites were capable of producing $o$-quinone metabolites by further oxidation steps and these metabolites were predicted for almost all investigated entactogens with exception of DiFMDA, 23).

The other important pathways that correspond to oxidative $\mathrm{N}$ - or $\mathrm{O}$-dealkylation, both catalyzed mostly by CYP1A2 and 2D6 with a higher probability, and also by 2C9, 2C19 and 3A4, but to a significantly less extent, to the corresponding amine or hydroxylamines metabolites were predicted for 18 entactogens. 
The oxidative deamination to corresponding carbonyl metabolites was predicted for 10 entactogens while the $N$-hydroxylation of formed amines to corresponding hydroxylamine metabolites were predicted in metabolic pathways of 6 entactogens.

All other pathways that involve either hydroxylation of alkyl chain or aromatic moiety or oxidation of yielded hydroxylamine were specific for particular entactogen and were predicted mostly to less extent as minor metabolites.

As expected, parent entactogen molecules were revealed with higher lipophilicity $(M \log P)$ in comparison to their corresponding o-quinone metabolites. The opposite was found for $o$-quinone metabolites in terms of their water solubility $\left(S+S_{\mathrm{w}}\right)$ for which the predicted scores were almost doubled in comparison to their parent molecules.

The predicted ADMET properties of investigated entactogen molecules were compared with the ADMET properties of their o-quinone metabolites. The ADMET_Risk, which corresponds to overall risk due to absorption, distribution, metabolism and excretion, showed entactogen molecules as the least favourable. The mutagenicity $(\mathrm{Mu})$ was predicted for MDMEO (14) as well as for the $o$-quinone metabolites of MDOH (12-M1) and MDMEO (14-M1), while the hepatotoxicity (Hp) were predicted in the set of the $o$-quinones for MDEA (4-M1), MDMEO (14-M1), MBDB (17-M1) and Ethyl-K (18-M1).

In addition to these risks the clearance of CYP catalyzing enzymes 1A2, 2C19, and 2D6 were also revealed as a CYP risk while in the set of $o$-quinone metabolites in addition to $\mathrm{Mu}$ and $\mathrm{Hp}$ the CYP risk due to clearance of 1A2 and the midazolam inhibition (mi) for some metabolites was revealed.

Among the investigated entactogen molecules, the MDMEO (14) was revealed as the molecule with the least favourable predicted safety profile for which the mutagenicity (Mu) was predicted for both, parent molecule, i.e., MDMEO (14) and its o-quinone metabolite (14-M1) for which the hepatotoxicity $(\mathrm{Hp})$ was also predicted. In addition, both parent molecule and its $o$-quinone metabolite can be metabolized to $o$-quinone 12-M1 for which mutagenicity was also predicted.

The four models useful for evaluation of environmental toxicity, i.e., the acute toxicity in Tetrahymena pyriformis (TOX_ATTP), the acute toxicity in Pimephales promelas, the fathead minnow (TOX_FHM) and the acute toxicity in Daphnia magna (TOX_DM) as well as bioconcentration factor (BCF) and biodegradability of entactogen molecules and corresponding $o$-quinone metabolites were used. Based on the predicted biodegradability, as well as on obtained computed scores for TOX_FHM, TOX_ATTP, TOX_DM and TOX BCF for the set of entactogen molecules 1-25 and the set of their $o$-quinone metabolites (1-M1 to $25-\mathrm{M} 1)$, it can be concluded that $o$-quinone metabolites are more ecotoxic comparing to their parent entactogens.

The computed molecular descriptors (MDs), ADMET properties and parameters relevant to environmental toxicity were used in the QSAR study. The best correlations were obtained with $M \log P$ with environmental toxic parameters TOX_FHM, TOX_ATTP, BCF and also with the predicted percentage of $o$-quinone metabolites yields which can be useful in further predictions of these properties for any new entactogen molecule or its metabolite.

Supplementary Materials are available upon request. 


\section{REFERENCES}

1. H. Jungaberle, S. Thal, A. Zeuch, A. Rougemont-Bücking, M. von Heyden, H. Aicher and M. Scheidegger, Positive psychology in the investigation of psychedelics and entactogens: a critical review, Neuropharmacology 142 (2018) 179-199; https://doi.org/10.1016/j.neuropharm.2018.06.034

2. D. E. Nichols, Differences between the mechanism of action of MDMA, MBDB, and the classic hallucinogens. Identification of a new therapeutic class: entactogens, J. Psychoactive Drugs 18 (1986) 305-313; https://doi.org/10.1080/02791072.1986.10472362

3. L. Iversen, M. White and R. Treble, Designer psychostimulants: pharmacology and differences, Neuropharmacology 87 (2014) 59-65; https://doi.org/10.1016/j.neuropharm.2014.01.015

4. R. W. Freudenmann, F. Öxler and S. Bernschneider-Reif, The origin of MDMA (ecstasy) revisited: The true story reconstructed from the original documents, Addiction 10 (2006) 1241-1245; https://doi. org//10.1111/j.1360-0443.2006.01511.x

5. K. S. Leung and L. B. Cottler, Ecstasy and other club drugs: a review of recent epidemiologic studies, Curr. Opin. Psychiatry. 21 (2008) 234-241; https://doi.org/10.1097/YCO.0b013e3282f9b1f1

6. E. Gouzoulis-Mayfrank, Differential actions of an entactogen compared to a stimulant and a hallucinogen in healthy humans, Heffter Rev. Psychodelic Res. 2 (2001) 64-72.

7. A. Aouidate, A. Ghaleb, M. Ghamali, S. Chtita, M. Choukrad, A. Sbai, M. Bouachrine and T. Lakhlifi, Combining DFT and QSAR studies for predicting psychotomimetic activity of substituted phenethylamines using statistical methods, J. Taibah. Univ. Sci. 10 (2016) 787-796; https://doi. org/10.1016/j.jtusci.2016.07.001

8. M. E. Liechti, Novel psychoactive substances (designer drugs): overview and pharmacology of modulators of monoamine signaling, Swiss. Med. Wkly. 145 (2015) w14043; https://doi.org/10.4414/ smw.2015.14043

9. D. M. McDowell and H. D. Kleber, MDMA: its history and pharmacology, Psychiatr. Ann. 24 (1994) 127-130.

10. A. C. Parrott, Chronic tolerance to recreational MDMA (3,4-methylenedioxymethamphetamine) or Ecstasy, J. Psychopharmacol. 19 (2005) 71-83; https://doi.org/10.1177/0269881105048900

11. A. C. Parrott, Human psychobiology of MDMA or 'Ecstasy': an overview of 25 years of empirical research, Hum. Psychopharmacol. 28 (2013) 289-307; https://doi.org/10.1002/hup.2318

12. T. S. Ray, Constructing the ecstasy of MDMA from its component mental organs: Proposing the primer/probe method, Med. Hypothesis 87 (2016) 48-60; https://doi.org/10.1016/j.mehy.2015.12.018

13. D. E. Nichols, Psychedelics, Pharmacol. Rev. 68 (2016) 264-355; https://doi.org/10.1124/pr.115.011478

14. F. X. Vollenweider, Brain mechanisms of hallucinogens and entactogens, Dialogues Clin Neurosci. 3 (2001) 265-279.

15. D. Quinteros-Muñoz, P. Sáez-Briones, G. Díaz-Véliz, S. Mora-Gutiérrez, M. Rebolledo-Fuentes, and B. K. Cassels, Behavioral profiles in rats distinguish among "ecstasy", methamphetamine and 2,5-dimethoxy-4-iodoamphetamine: Mixed effects for "ecstasy" analogues, Behav. Neurosci. 124 (2010) 662-676, https://doi.org/10.1037/a0020827

16. A. Garcia-Romeu, B. Kersgaard and P. H. Addy, Clinical applications of hallucinogens: A Review, Exp. Clin. Psychphamacol. 24 (2016) 229-268; https://doi.org/10.1037/pha0000084

17. M. C. Mithoefer, M. T. Wagner, A. T. Mithoefer, L. Jerome and R. Doblin, The safety and efficacy of \pm 3 ,4-methylenedioxymethamphetamine-assisted psychotherapy in subjects with chronic, treatment resistant posttraumatic stress disorder: the first randomized controlled pilot study, J. Psychopharmacol. 25 (2010) 439-452; http://dx.doi.org/10.1177/0269881110378371

18. A. C. Wagner, M. C. Mithoefer, A. T. Mithoefer and C. M. Monson, Combining cognitive-behavioral conjoint therapy for PTSD with 3,4-methylenedioxymethamphetamine (MDMA): A case example, J. Psychoactive Drugs 51 (2019) 166-173; https://doi.org/10.1080/02791072.2019.1589028

19. W. Barone, J. Beck, M. Mitsunaga-Whitten and P. Perl, Perceived benefits of MDMA-assisted psychotherapy beyond symptom reduction: qualitative follow-up study of a clinical trial for individuals 
with treatment-resistant PTSD, J. Psychoactive Drugs 51 (2019) 199-208; https://doi.org/10.1080/027910 72.2019.1580805

20. A. L. Danforth, Embracing neurodiversity in psychedelic science: A mixed-methods inquiry into the MDMA experiences of autistic adults, J. Psychoactive Drugs 51 (2019) 146-154; https://doi.org/10.1 080/02791072.2019.1587116

21. E. Dyck, Psychedelics and dying care: A historical look at the relationship between psychedelics and palliative care, J. Psychoactive Drugs 51 (2019) 102-107; https://doi.org/10.1080/02791072.2019.1581308

22. MDMA Investigator's Brochure U.S. 10th Edition: 10 July 2018, https://s3-us-west-1.amazonaws.com/ mapscontent/research-archive/mdma/MAPS_2018_MDMA_Investigators_Brochure_ Edition10_10JUL2018.pdf.

23. A. P. Hall and J. A. Henry, Acute toxic effects of 'Ecstasy' (MDMA) and related compounds: overview of pathophysiology and clinical management, Br. J. Anaesth. 96 (2006) 678-685; https://doi. org/10.1093/bja/ael078

24. M. Ferigolo, A. G. da S. Machado, N. B. Oliveira and H. M. T. Barros, Ecstasy intoxication: the toxicological basis for treatment, Rev. Hosp. Clín. Fac. Med. S. Paulo 58 (2003) 332-341.

25. M. J. Baggott, K. J. Garrison, J. R. Coyle, G. P. Galloway, A. J. Barnes, M. A. Huestis and J. E. Mendelson, Effects of the psychedelic amphetamine MDA (3,4-methylenedioxyamphetamine) in healthy volunteers, J. Psychoactive Drugs 51 (2019) 108-117; https://doi.org/10.1080/02791072.2019.1593560

26. M. Edland-Gryt, S. Sandberg and W. Pedersen, From ecstasy to MDMA: Recreational drug use, symbolic boundaries, and drug trends, Int. J. Drug Policy 5 (2017) 1-8; https://doi.org/ 10.1016/j.drugpo.2017.07.030

27. A. C. Parrott, L. A. Downey, C. A. Roberts, C. Montgomery, R. Bruno and H. C. Fox, Recreational 3,4-methylenedioxymethamphetamine or 'ecstasy': current perspective and future research prospects, J. Psychopharmacol. 31 (2017) 959-966; https://doi.org/10.1177/0269881117711922

28. R. Bruno, A. J. Matthews, M. Dunn, R. Alati, F. McIlwraith, S. Hickey, L. Burns and N. Sindicich, Emerging psychoactive substance use among regular ecstasy users in Australia, Drug Alcohol Depend. 124 (2012) 19-25; https://doi.org/10.1016/j.drugalcdep.2011.11.020

29. M. D. Krasowski, Drug-assisted Sexual Assaults: Toxicology, Fatality, and Analytical Challenge, in Critical Issues in Alcohol and Drugs of Abuse Testing (Ed. A. Dasgupta), 2nd ed., Academic Press, Elsevier Inc., London 2019, p.p. 225-236.

30. H. Kalant, The pharmacology and toxicology of "ecstasy" (MDMA) and related drugs, CMAJ 165 (2001) 917-928.

31. R. de la Torre, M. Farré, P. N. Roset, C. H. Lopez, M. Mas, J. Ortuño, E. Menoyo, N. Pizarro, J. Segura and J. Cami, Pharmacology of MDMA in humans, Ann. N. Y. Acad Sci. 914 (2000) 225-937; https://doi. org/ 10.1111/j.1749-6632.2000.tb05199.x

32. S. B. Holmes, A. K. Banerjee and W. D. Alexander, Hyponatraemia and seizures after ecstasy use, Postgrad. Med. J. 75 (1999) 32-33; https://doi.org/ 10.1136/pgmj.75.879.32

33. K. A. Graeme, New drugs of abuse, Emerg. Med. Clin. North. Am. 18 (2000) 625-636; https://doi. org/10.1016/S0733-8627(05)70150-4

34. C. Eiden, P. Cathala, N. Fabresse, Y. Galea, J. C. Mathieu-Daude, E. Baccino and E. H. Peyrière, A case of drug-facilitated sexual assault involving 3,4-methylenedioxy-methylamphetamine, J. Psychoactive Drugs 45 (2013) 94-97; https://doi.org/10.1080/02791072.2013.763573

35. A. L. van Nuijs, S. Castiglioni, I. Tarcomnicu, C. Postigo, M. Lopez de Alda, H. Neels, E. Zuccato, D. Barcelo and A. Covaci, Illicit drug consumption estimations derived from wastewater analysis: a critical review, Sci. Total. Environ. 409 (2011) 3564-3577; https://doi.org/10.1016/j.scitotenv.2010.05.030

36. E. Zuccato and S. Castiglioni, Illicit drugs in the environment, Philos. Trans. A Math. Phys. Eng. Sci. 367 (2009) 3965-3978; https://doi.org/10.1098/rsta.2009.0107

37. S. Karolack, T. Nefau, E. Bailly, A. Solgadi and Y. Levi, Estimation of illicit drugs consumption by wastewater analysis in Paris area (France), Forensic Sci. Int. 200 (2010) 153-160; https://doi.org/1016/j. forsciint.2010.04.007 
38. M. Huerta-Fontela, M. T. Galceran, J. Martin-Alonso and F. Ventura, Occurrence of psychoactive stimulatory drugs in wastewaters in north-eastern Spain, Sci. Total. Environ. 397 (2008) 31-40; https:// doi.org/10.1016/j.scitotenv.2008.02.057

39. M. S. Lowless, M. Waldman, R. Franczkiewicz and R. D. Clark, Using Chemoinformatics in Drug Discovery, in New Approaches to Drug Discovery, Handbook of Experimental Pharmacology (Eds. U. Nielsch, U. Fuhrmann, S. Jaroch), Springer, Berlin 2015, pp. 232, 139-170.

40. C. L. Russom, S. P. Bradbury, S. J. Broderius, D. E. Hammermeister and R. A. Drummond, Predicting modes of toxic action from chemical structure: Acute toxicity in the fathead minnow (Pimephales promelas), Environ. Toxicol. 16 (1997) 948-967; https://doi.org/10.1002/etc.5620160514

41. H. Zhu, A. Tropsha, D. Fourches, A. Varnek, E. Papa, P. Gramatica, T. Oberg, P. Dao, A. Cherkasov and I. V. Tetko, Combinatorial QSAR modeling of chemical toxicants tested against Tetrahymena pyriformis, J. Chem. Inf. Model. 48 (2008) 766-784; https://doi.org/10.1021/ci700443v

42. A. Golbamaki, A. Cassano, A. Lombardo, Y. Moggio, M. Colafranceschi and E. Benfenati, Comparison of in silico models for prediction of Daphnia magna acute toxicity, SAR QSAR Environ. Res. 25 (2014) 673-694; https://doi.org/10.1080/1062936X.2014.923041

43. J. L. Hamelink and A. Spacie, Fish and chemicals: The process of accumulation, Annu. Rev. Pharmacol. Toxicol. 17 (1977) 167-177; https://doi.org/10.1146/annurev.pa.17.040177.001123

44. Z. Zhan, L. Li, S. Tian, X. Zhen and Y. Li, Prediction of chemical biodegradability using computational methods, Mol. Simulat. 43 (2017) 1277-1290; https://doi.org/10.1080/08927022.2017.1328556

45. J. Kirchmair, M. J. Williamson, J. D. Tyzack, L. Tan, P. J. Bond, A. Bender and Robert C. Glen, Computational prediction of metabolism: sites, products, SAR, P450. Enzyme dynamics, and mechanisms, J. Chem. Inf. Model. 52 (2012) 617-648; dx.doi.org/10.1021/ci200542m

46. T. T. Abraham, A. J. Barnes, R. H. Lowe, E. A. Kolbrich Spargo, G. Milman, S. O. Pirnay, D. A. Gorelick, R. S. Goodwin and M. A. Huestis, Urinary MDMA, MDA, HMMA, and HMA excretion following controlled MDMA administration to humans, J. Anal. Toxicol. 33 (2009) 439-446; https://doi. org/10.1093/jat/33.8.439

47. C. Burgess, A. Donohoe and M. Gill, Agony and ecstasy: a review of MDMA effects and toxicity, Eur. Psychiatry 15 (2000) 287-294; https://doi.org/10.1016/S0924-9338(00)00396-5

48. R. L. Hartman, N. A. Desrosiers, A. J. Barnes, K. Yun, K. B. Scheidweiler, E. A. Kolbrich-Spargo, D. A. Gorelick, R. S. Goodwin and M. A. Huestis, 3,4-Methylenedioxymethamphetamine (MDMA) and metabolites disposition in blood and plasma following controlled oral administration, Anal. Bioanal. Chem. 406 (2014) 587-599; https://doi.org/10.1007/s00216-013-7468-y

49. F. Schifano, A bitter pill. Overview of ecstasy (MDMA, MDA) related fatalities, Psychopharmacology 173 (2004) 242-248; https://doi.org/10.1007/s00213-003-1730-5

50. D. Trachsel, M. Hadorn and F. Baumberger, Synthesis of fluoro analogues of 3,4-(methylenedioxy) amphetamine (MDA) and its derivatives, Chem. Biodivers. 3 (2006) 326-336; https://doi.org/10.1002/ cbdv.200690035

51. R. G. Pearce, R. W. Setzer, J. L. Davis and J. F. Wambaugh, Evaluation and calibration of highthroughput predictions of chemical distribution to tissues, J. Pharmacokinet. Pharmacodyn. 44 (2017) 549-565; https://doi.org/10.1007/s10928-017-9548-7

52. F. Cheng, Y. Ikenaga, Y. Zhou, Y. Yu, W. Li, J. Shen, Z. Du, L. Chen, C. Xu, G. Liu, P. W. Lee, Y. Tang, In silico assessment of chemical biodegradability, J. Chem. Inf. Model. 52 (2012) 655-669; https://doi. org/10.1021/ci200622d

53. L. Moriguchi, S. Hirono, Q. Liu, I. Nakagome and Y. Matsushita, Simple method of calculating octanol/water partition coefficient, Chem. Pharm. Bull. 40 (1992) 127-130.

54. T. I. Oprea, J. Gottfries, V. Sherbukhin, P. Svensson and T. C. Kuhler, Chemical information management in drug discovery: optimizing the computational and combinatorial chemistry interfaces, J. Mol. Graph. Model. 18 (2000) 512-524; https://doi.org/10.1016/S1093-3263(00)00066-8 